\title{
PENGARUH LEADER MEMBER EXCHANGE (LMX) TERHADAP KINERJA PEGAWAI (Studi pada Pegawai di Politeknik Ilmu Pelayaran Semarang)
}

\author{
Awel Suryadi
}

Dosen Program Studi KALK PIP Semarang

\begin{abstract}
ABSTRAK
Target dari penelitian ini untuk menguji dan menganalisa Leader Member Exchange (LMX) untuk kinerja pegawai di Politeknik Ilmu Pelayaran Semarang. Pada penelitian ini tentang populasi pegawai Politeknik Ilmu Pelayaran Semarang berjumlah 190 orang. Pengambilan contoh dengan teknik stratifikasi porposional kelompok acak. Ketetapan dari jumlah contoh menggunakan rumus slovin didapat dari 129 responder. Analisis data menggunakan analisis regresi linear ganda. Leader Member Exchange (LMX) mempunyai pengaruh positif dan signifikan pada kinerja dari pegawai.
\end{abstract}

\section{Kata kunci: Leader Member Exchange (LMX), kinerja pegawai}

\section{PENDAHULUAN}

\section{A. Latar Belakang Penelitian}

Keberadaan sumber daya manusia di dalam suatu organisasi memegang peranan sangat penting. Tenaga kerja memiliki potensi yang besar untuk menjalankan aktivitas organisasi. Potensi setiap sumber daya manusia yang ada dalam organisasi harus dapat dimanfaatkan dengan sebaikbaiknya sehingga mampu memberikan output optimal. Tercapainya tujuan organisasi tidak hanya tergantung pada peralatan modern, sarana dan prasarana yang lengkap, tetapi justru lebih tergantung pada manusia yang melaksanakan pekerjaan tersebut. Keberhasilan suatu organisasi sangat dipengaruhi oleh kinerja individu pegawainya. Kinerja pegawai menurut Mangkunegara (2009) sebagai hasil kerja secara kualitas dan kuantitas yang dapat dicapai oleh seorang pegawai dalam melaksanakan tugas sesuai dengan tanggung jawab yang diberikan kepadanya.

Setiap organisasi maupun perusahaan akan selalu berusaha untuk meningkatkan kinerja pegawai, dengan harapan apa yang menjadi tujuan organisasi akan tercapai. Dalam meningkatkan kinerja pegawainya organisasi menempuh beberapa cara misalnya melalui Leader Member Exchange (LMX), karakteristik pekerjaan serta pemberian motivasi. Melalui prosesproses tersebut, pegawai diharapkan akan lebih memaksimalkan tanggung jawab atas pekerjaan mereka.

Leader Member Exchange (LMX) adalah cara seorang pemimpin mempengaruhi perilaku bawahan, agar mau bekerja sama dan bekerja secara produktif untuk mencapai tujuan organisasi. Kepemimpinan (leadership) yang ditetapkan oleh seorang manajer dalam organisasi dapat menciptakan intregasi yang serasi dan mendorong gairah kerja pegawai untuk mencapai sasaran yang maksimal sehingga akan dapat meningkatkan kinerja pegawai (Umar Husain, 2011).

Penelitian mengenai pengaruh Leader Member Exchange (LMX) terhadap kinerja pegawai pernah dilakukan oleh Kimberley Breevaart (2015), Ahda Saiful Aziz (2012) dan Frans Agustinis (2013) yang menghasilkan Leader Member Exchange (LMX) berpengaruh positif dan signifikan terhadap kinerja pegawai. 
Berbeda dengan hasil penelitian yang dilakukan oleh Hentry Sukmasari (2011) dan Utari (2015) yang menghasilkan Leader Member Exchange (LMX) tidak berpengaruh signifikan terhadap kinerja pegawai.

Kajian penelitian mengenai pengaruh Leader Member Exchange (LMX) terhadap kinerja pegawai akan dilakukan pada pegawai Dosen dan Instruktur di Politeknik Ilmu Pelayaran Semarang. Politeknik Ilmu Pelayaran Semarang adalah salah satu Lembaga Pendidikan Maritim negeri dibawah naungan Kementerian Perhubungan dan satusatunya yang berada di Jawa Tengah, yang berlokasi di Jalan Singosari 2A Semarang dengan tugas pokok membina dan mencetak lulusan perwira-perwira kapal niaga, baik kapal-kapal milik Negara maupun kapal-kapal swasta.

Pada saat ini, Politeknik Ilmu Pelayaran Semarang terus berupaya secara maksimal untuk menghasilkan lulusan Perwira Pelayaran yang handal dan siap bersaing di kancah nasional maupun internasional, sesuai dengan visi dan misinya yakni Visi Politeknik Ilmu Pelayaran Semarang adalah terciptanya kader-kader perwira pelayaran niaga yang handal, profesional dan berbudi pekerti luhur sesuai nilai-nilai Pancasila untuk memajukan bangsa, dan Misi Politeknik Ilmu Pelayaran Semarang yaitu memberikan pelayanan pendidikan dan pelatihan pelayaran yang memenuhi standar kualitas nasional maupun internasional, melaksanakan penelitian dan pengabdian kepada masyarakat dalam rangka penguasaan dan pengembangan ilmu pengetahuan dan teknologi di bidang pelayaran, melaksanakan tata kelola kelembagaan yang dinamis, transparan dan akuntabel, memberdayakan dan mengembangkan sarana dan prasarana serta segenap sumber daya lainnya guna menunjang pelaksanaan tugas pokok dan fungsi kelembagaan secara efektif dan efisien serta membina hubungan kerjasama dengan berbagai instansi terkait termasuk alumni, baik di dalam maupun di luar negeri.

Berdasarkan latar belakang tersebut di atas, maka peneliti akan menguji tentang pengaruh Leader Member Exchange (LMX) terhadap kinerja pegawai (Studi pada Pegawai di Politeknik Ilmu Pelayaran Semarang).

\section{B. Perumusan Masalah}

Agar pembahasan masalah dalam penelitian lebih jelas, maka perlu adanya perumusan masalah secara sistematis sebagai berikut : "Bagaimana pengaruh Leader Member Exchange (LMX) terhadap kinerja pegawai Politeknik Ilmu Pelayaran Semarang?"

\section{Tujuan Penelitian}

Adapun tujuan penelitian ini adalah : "Untuk menguji dan menganalisis pengaruh Leader Member Exchange (LMX) terhadap kinerja pegawai Politeknik Ilmu Pelayaran Semarang”.

\section{Manfaat Penelitian}

Adapun manfaat yang dapat diambil dari penelitian ini adalah :

1. Manfaat praktis penelitian ini diharapkan dapat memberikan informasi tambahan bagi pihakpihak yang berkepentingan dalam dunia organisasi tentang Leader Member Exchange (LMX) dan kinerja pegawai sehingga dapat dilakukan usaha-usaha untuk meningkatkannya.

2. Manfaat teoritis, hasil penelitian ini diharapkan dapat membantu mengembangkan teori yang berkaitan dengan Leader Member Exchange (LMX) serta kinerja pegawai.

3. Manfaat kebijakan, hasil penelitian ini diharapkan dapat memberikan sumbangan pada pihak-pihak yang berkepentingan dalam rangka mengambil kebijakan yang berkaitan dengan Leader Member Exchange (LMX) serta kinerja pegawai. 
Sebagai masukan bagi penelitian selanjutnya dalam mengembangkan penelitian mengenai Leader Member Exchange (LMX) serta kinerja pegawai.

\section{LANDASAN TEORI}

A. Hubungan Antar Variabel dan Pengembangan Hipotesis

1. Pengaruh Leader Member Exchange (LMX) terhadap kinerja pegawai

Leader Member Exchange (LMX) adalah cara seorang pemimpin mempengaruhi perilaku bawahan, agar mau bekerja sama dan bekerja secara produktif untuk mencapai tujuan organisasi. Kepemimpinan (leadership) yang ditetapkan oleh seorang manajer dalam organisasi dapat menciptakan integrasi yang serasi dan mendorong gairah kerja pegawai untuk mencapai sasaran yang maksimal sehingga akan dapat meningkatkan kinerja pegawai (Umar Husain, 2011).

Penelitian mengenai pengaruh Leader Member Exchange (LMX) terhadap kinerja pegawai pernah dilakukan oleh Kimberley Breevaart (2015), Ahda Saiful Aziz (2012) dan Frans Agustinis (2013) yang menghasilkan Leader Member Exchange (LMX) berpengaruh positif dan signifikan terhadap kinerja pegawai. Berdasarkan hal tersebut, maka dalam penelitian ini dirumuskan hipotesis sebagai berikut:

$\mathrm{H}$ : Leader Member Exchange (LMX) berpengaruh positif terhadap kinerja pegawai Politeknik Ilmu Pelayaran Semarang

\section{Model Penelitian}

Hal yang penting dalam pengelolaan sumber daya manusia adalah mengenai kinerja pegawai. Kinerja pegawai sebagai hasil kerja secara kualitas dan kuantitas yang dapat dicapai oleh seseorang pegawai dalam melaksanakan tugas sesuai dengan tanggung jawab yang diberikan kepadanya. Hal yang mendukung kinerja pegawai tersebut adalah Leader Member Exchange (LMX). Berdasarkan uraian tersebut diatas maka dapat disusun kerangka teoritis sebagai berikut :

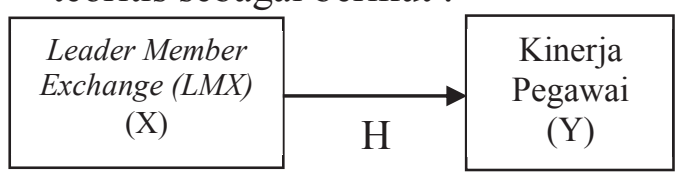

Gambar Kerangka Model Penelitian

\section{METODE PENELITIAN}

\section{A. Populasi Penelitian}

Populasi menurut Sutrisno Hadi (2006) adalah sekumpulan dari seluruh elemenelemen yang dalam hal ini diartikan sebagai obyek penelitian. Adapun populasi dalam penelitian ini adalah Pegawai Politeknik IImu Pelayaran Semarang yang berjumlah 190 orang.

\section{B. Sampel Penelitian}

Sampel adalah sebagian atau wakil populasi yang akan diteliti (Sutrisno Hadi, 2006). Sampel dalam penelitian ini adalah pegawai Politeknik Ilmu Pelayaran Semarang. Pengambilan sampel dengan teknik random sampling yaitu menentukan jumlah sampel secara acak semua anggota populasi mempunyai kesempatan yang sama untuk dijadikan sampel (Sutrisno Hadi, 2006). Penentuan jumlah sampel menggunakan rumus Slovin diketahui sebesar 129 orang.

\section{Definisi Konsep, Operasional Dan Pengukuran Variabel}


Tabel Definisi Konsep, Operasional dan Pengukuran Variabel

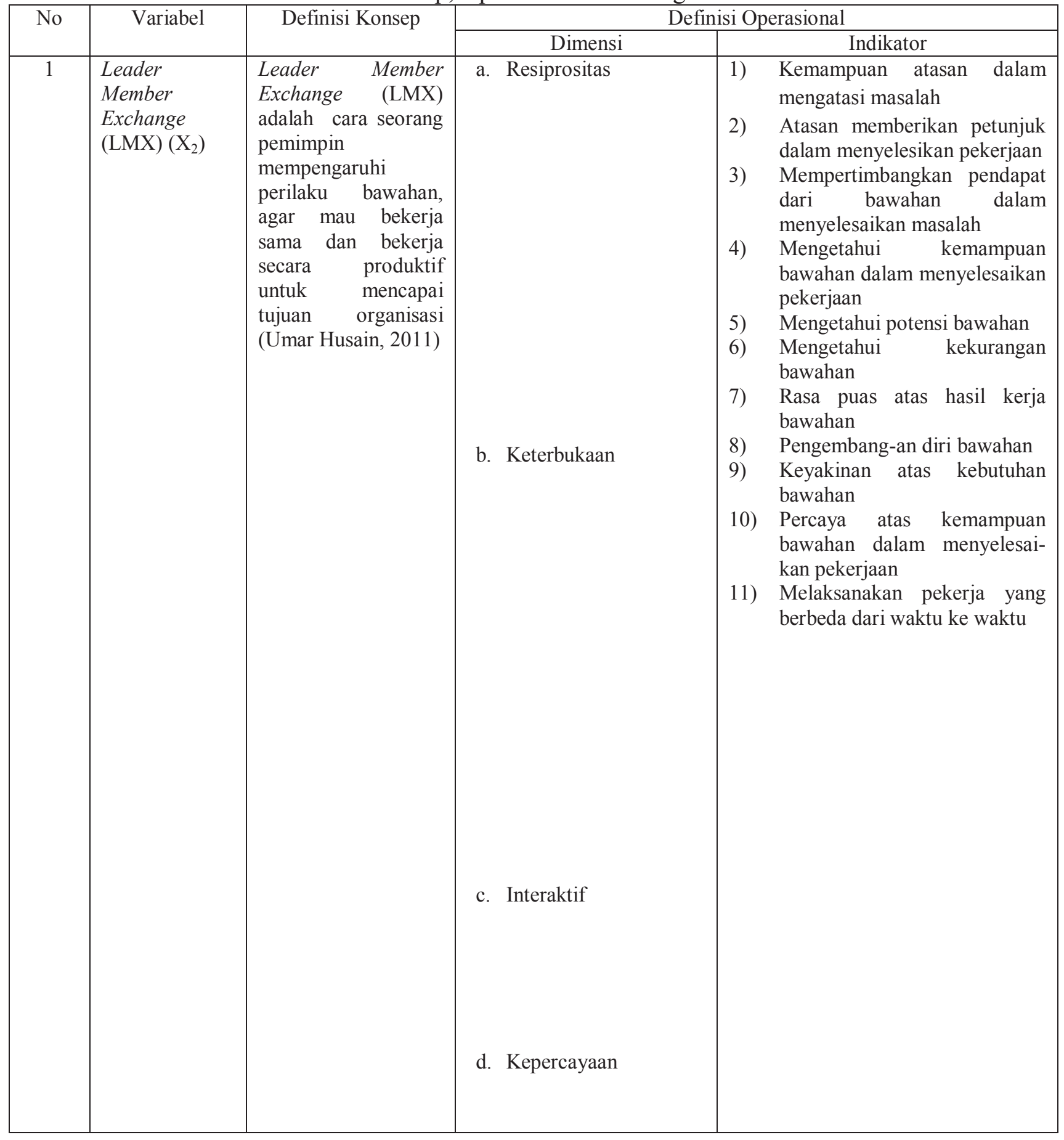




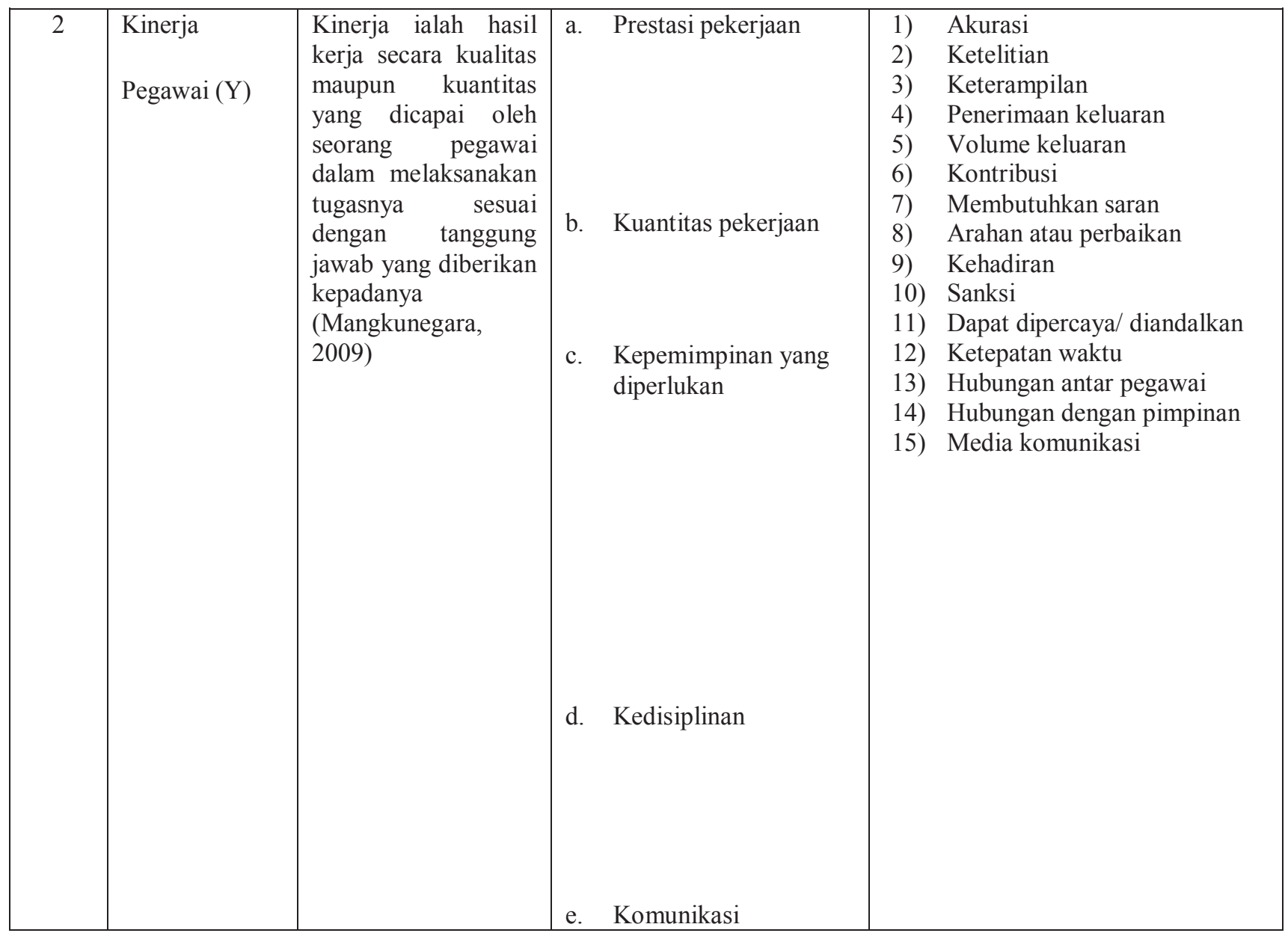

\section{Jenis dan Sumber Data}

Dalam penelitian ini menggunakan data primer. Data primer merupakan data yang bersumber dari tangan pertama, data yang diambil menggunakan cara kuesioner. Kuesioner merupakan daftar pertanyaan yang dipakai sebagai pedoman untuk mengadakan tanya jawab dengan responden mengenai pengaruh Leader Member Exchange (LMX) pekerjaan terhadap kinerja pegawai.

\section{E. Uji Instrumen Penelitian}

\section{Uji Validitas}

Uji validitas digunakan untuk mengukur valid tidaknya suatu indikator yang berbentuk kuesioner. Suatu kuesioner dikatakan valid jika pertanyaan mampu untuk mengungkapkan suatu yang akan diukur oleh kuesioner tersebut.
Dalam penelitian ini, uji validitas menggunakan analisis faktor yaitu dengan menguji apakah butir-butir indikator atau kuesioner yang digunakan dapat mengkonfirmasikan sebuah faktor atau konstruk. Jika masing-masing pertanyaan merupakan indikator pengukur maka memiliki KMO diatas 0,5 dan signifikansi dibawah 0,05 serta memiliki nilai kriteria loading faktor pengujian sebagai berikut (Ghozali, 2006) :

Loading faktor > rule of tumb $(0,4)$ berarti valid

Loading faktor < rule of tumb $(0,4)$ berarti tidak valid

2. Uji Reliabilitas

Suatu alat ukur instrumen disebut reliabel, jika alat tersebut dalam mengukur segala sesuatu pada waktu berlainan, menunjukkan hasil yang relatif sama. Pengukuran 
reliabilitas dapat dilakukan dengan koefisien Alpha Cronbach menggunakan SPSS For Windows (Ghozali, 2006) dengan kriteria :

Bila nilai alpha $>0,7$ maka instrumen reliabel

Bila nilai alpha $<0,7$ maka instrumen tidak reliabel

\section{F. Uji Model}

Uji model data dalam penelitian ini menggunakan :

1. Analisis Regresi Berganda

Suatu analisa yang digunakan untuk mengetahui persamaan regresi yang menunjukkan persamaan antara variabel dependent dan variabel independent dengan rumus sebagai berikut :

$\mathrm{Y}=\alpha+\beta \mathrm{X}+\mathrm{e}$

Keterangan :

$\alpha=$ Konstanta

$\mathrm{Y}=$ Kinerja Pegawai

$\mathrm{X}=$ Leader Member Exchange

(LMX)

$\beta=$ Koefisien regresi

$\mathrm{e}=$ Error

2. Koefisien determinasi

Koefisien determinasi digunakan untuk mengetahui besarnya persentase goodness of fit dari variabel independent terhadap variabel dependent (Ghozali, 2006).

3. Uji F

Uji $\mathrm{F}$ untuk menguji pengaruh antara variabel independent terhadap variabel dependent secara simultan atau bersama-sama (Ghozali, 2006) dengan kriteria taraf signifikan $(\alpha)<0,05$.

4. Uji Hipotesis

Uji hipotesis menggunakan uji $\mathrm{t}$ dengan model regresi linier berganda yaitu untuk mengidentifikasi pengaruh variabel independent terhadap variabel dependent dengan menggunakan SPSS (Ghozali, 2006). Adapun kriteria hipotesis diterima bila taraf signifikan $(\alpha)<0,05$.

\section{HASIL PENELITIAN DAN \\ PEMBAHASAN}

\section{A. Hasil Penelitian}

Tabel Ringkasan Uji regresi Linier

\begin{tabular}{|c|l|c|c|c|c|c|c|c|}
\hline \multirow{2}{*}{ No } & \multirow{2}{*}{$\begin{array}{l}\text { Hubungan } \\
\text { Variabel }\end{array}$} & \multicolumn{7}{|c|}{ Model Regresi Persamaan } \\
\cline { 3 - 9 } & & $\mathrm{R}^{2}$ & $\mathrm{~F}$ & Sig. & $\mathrm{B}$ & $\mathrm{t}$ & Sig. & Ket \\
\hline $\mathbf{1}$ & $\begin{array}{l}\text { Pengaruh } \\
\text { LMX terha- } \\
\text { dap kinerja } \\
\text { pega-wai }\end{array}$ & $\mathbf{0 , 2 1 9}$ & $\mathbf{1 2 , 9 9 5}$ & $\mathbf{0 , 0 0}$ & 0,169 & 2,049 & $\begin{array}{l}0,04 \\
3\end{array}$ & $\begin{array}{l}\text { Penga } \\
\text { ruh } \\
\text { Positif } \\
\text { (H } \\
\text { diterim } \\
\text { a) }\end{array}$ \\
\hline
\end{tabular}

Berganda

\section{Analisis Regresi Berganda}

Hasil persamaan regresi $\mathbf{Y}_{\mathbf{2}}=$ 0,169 X. Berdasarkan persamaan di atas terlihat bahwa LMX mempunyai pengaruh positif terhadap kinerja pegawai dengan nilai koefisien regresi sebesar LMX $=0,169$.

\section{Uji Model}

a. Uji F

Uji F dilakukan untuk menguji kesesuaian model yang digunakan untuk analisis. Model dinyatakan fit jika nilai sig $\mathrm{F}$ lebih kecil dari 0,05. Variabel bebas yang dimasukkan dalam model mempunyai pengaruh secara bersama-sama/simultan terhadap variabel terikat.

Hasil F hitung 12,995 dengan tingkat signifikan $0,000<0,05$ maka LMX mempunyai pengaruh positif dan signifikan terhadap kinerja pegawai

b. Uji Koefisien Determinasi $\left(\mathrm{R}^{2}\right)$

Koefisien determinasi $\left(\mathrm{R}^{2}\right)$ dimana dalam penelitian ini menggunakan Adjusted $R$ Square mengukur seberapa jauh kemampuan variabel independen 


\begin{abstract}
dalam menjelaskan variasi variabel dependen.

Hasil koefisien determinasi diperoleh angka koefisien Adjusted R Square sebesar 0,219. Hal ini berarti bahwa sebesar $21,9 \%$ kinerja pegawai dapat dijelaskan oleh LMX. Sedangkan sisanya $100 \%-21,9 \%=78,1 \%$ dijelaskan oleh sebab-sebab yang lain di luar variabel LMX.
\end{abstract}

\section{Pengujian Hipotesis}

Pengujian hipotesis menggunakan uji secara parsial (uji t) untuk menguji pengaruh variabel independent terhadap variabel dependent secara parsial dengan kriteria taraf signifikan sebesar 0,05.

Pengaruh LMX terhadap kinerja pegawai hasil hipotesis pertama LMX menghasilkan koefisien regresi 0,169 dan tingkat signifikan $0,043<0,05$ sehingga secara parsial (individu) terdapat pengaruh positif dan signifikan terhadap kinerja pegawai. Dengan demikian hipotesis (H): Leader Member Exchange (LMX) berpengaruh positif dan signifikan terhadap kinerja pegawai Politeknik Ilmu Pelayaran Semarang, diterima.
a. Hasil hipotesis
kedua

karakteristik pekerjaan

menghasilkan koefisien regresi

0,203 dan tingkat signifikan $0,013<0,05$ sehingga secara parsial (individu) terdapat pengaruh positif dan signifikan terhadap kinerja pegawai. Dengan demikian hipotesis kedua $(\mathrm{H} 2)$ : Karakteristik pekerjaan berpengaruh positif dan signifikan terhadap kinerja pegawai Politeknik Ilmu Pelayaran Semarang, diterima.

\section{B. Pembahasan}

Hasil penelitian yang dilakukan untuk mengetahui pengaruh Leader Member Exchange (LMX) terhadap kinerja pegawai pada Pegawai di
Politeknik Ilmu Pelayaran Semarang adalah sebagai berikut :

1. Pengaruh LMX terhadap kinerja pegawai hasil penelitian Leader Member Exchange (LMX) berpengaruh positif dan signifikan terhadap kinerja pegawai Politeknik Ilmu Pelayaran Semarang. Hasil penelitian ini sama dengan penelitian yang dilakukan oleh Kimberley Breevaart (2015), Ahda Saiful Aziz (2012) dan Frans Agustinis (2013) yang menghasilkan Leader Member Exchange (LMX) berpengaruh positif dan signifikan terhadap kinerja pegawai.

2. Leader Member Exchange (LMX) adalah cara seorang pemimpin mempengaruhi perilaku bawahan, agar mau bekerja sama dan bekerja secara produktif untuk mencapai tujuan organisasi. Kepemimpinan (leadership) yang ditetapkan oleh seorang manajer dalam organisasi dapat menciptakan intregasi yang serasi dan mendorong gairah kerja pegawai untuk mencapai sasaran yang maksimal sehingga akan dapat meningkatkan kinerja pegawai (Umar Husain, 2011).

\section{PENUTUP}

\section{A. Kesimpulan}

Berdasarkan penelitian mengenai pengaruh Leader Member Exchange (LMX) dan karakteristik pekerjaan terhadap kinerja pegawai pada Pegawai di Politeknik Ilmu Pelayaran Semarang dapat diperoleh kesimpulan sebagai berikut :

1. Leader Member Exchange (LMX) berpengaruh positif dan signifikan terhadap kinerja pegawai. Dengan demikian apabila Leader Member Exchange (LMX) dapat diterima, maka kinerja pegawai akan meningkat.

2. Karakteristik pekerjaan berpengaruh positif dan signifikan terhadap 
kinerja pegawai. Dengan demikian apabila karakteristik pekerjaan pegawai semakin tepat, maka kinerja pegawai akan meningkat

\section{B. Implikasi}

\section{Implikasi Teori}

Kinerja pegawai dipengaruhi secara positif dan signifikan oleh Leader Member Exchange (LMX). Dengan kata lain semakin baik Leader Member Exchange (LMX) Politeknik IImu Pelayaran Semarang maka akan semakin baik pula kinerja pegawai pada Politeknik IImu Pelayaran Semarang. Leader Member Exchange (LMX) adalah cara seorang pemimpin mempengaruhi perilaku bawahan, agar mau bekerja sama dan bekerja secara produktif untuk mencapai tujuan organisasi. Kepemimpinan (leadership) yang ditetapkan oleh seorang manajer dalam organisasi dapat menciptakan integrasi yang serasi dan mendorong gairah kerja pegawai untuk mencapai sasaran yang maksimal sehingga akan dapat meningkatkan kinerja pegawai.

\section{Implikasi Manajerial}

Berdasarkan hasil penelitian yang telah dilakukan, beberapa kebijakan manajerial yang dapat disarankan adalah sebagai berikut :

Politeknik Ilmu Pelayaran Semarang perlu meningkatkan lagi variabel LMX karena mempunyai pengaruh terkecil terhadap kinerja pegawai dengan memperbaiki melalui indikator LMX yang masih kurang seperti pemimpin kurang banyak memberikan petunjuk-petunjuk dalam menyelesaikan pekerjaan, kurang mempertimbangkan pendapat bawahan dalam menyelesaikan masalah, kurang memperhatikan kebutuhan bawahan dan pimpinan kurang memberikan kesempatan pengembangan diri bawahannya.

\section{Keterbatasan Penelitian}

Evaluasi atas hasil penelitian ini harus mempertimbangkan beberapa batasan yang mungkin mempengaruhi hasil. Oleh karena itu batasan ini perlu lebih diperhatikan untuk penelitian berikutnya. Penelitian apapun dan dengan desain yang sempurna apapun pasti mempunyai kelemahan, tak terkecuali penelitian ini. Kelemahan sekaligus merupakan keterbatasan dari penelitian ini antara lain

1. Penelitian hanya mengambil pegawai pada di lingkungan Politeknik Ilmu Pelayaran Semarang saja, untuk itu sebaiknya pada penelitian berikut lebih memperluas objek penelitian, sehingga dapat mencerminkan keakuratan data penelitian secara keseluruhan.

2. Subjektifitas penelitian masih kurang karena dinilai oleh pegawai sendiri, dimana seharusnya lebih baik yang menilai adalah orang lain.

3. Terdapat banyak variabel yang dapat mempengaruhi kinerja pegawai. Dalam penelitian ini hanya diteliti dengan satu variabel yang mempengaruhi kinerja pegawai.

\section{Agenda Penelitian Mendatang}

Setelah penelitian ini memberikan hasil atas perumusan masalah yang diajukan dan telah memberikan kesimpulan penelitian, selanjutnya adalah mengetengahkan saran-saran bagi penelitian yang akan datang, antara lain :

1. Sampel penelitian perlu diperbanyak lagi, tidak hanya terbatas pada 129 pegawai di lingkungan Politeknik IImu Pelayaran Semarang, sehingga dapat digeneralisasi hasil-hasil penelitian mengenai pengaruh LMX terhadap kinerja pegawai.

2. Berdasarkan hasil Adjusted $R$ Square diperoleh $26,8 \%$ yang mempengaruhi kinerja pegawai dalam penelitian ini hanya menggunakan faktor LMX masih banyak faktor yang belum dipakai seperti kompensasi, promosi jabatan, pendidikan dan pelatihan 
Adanya keterbatasan ruang lingkup penelitian, maka untuk penelitian yang akan datang dapat dilakukan penelitian pada perusahaan yang lain, agar dapat diketahui konsistensi teori yang telah ada sehingga dapat dikembangkan teori-teori lain dalam meningkatkan tingkat kinerja pegawai pada umumnya.

\section{DAFTAR PUSTAKA}

Aziz, Ahda Saiful. 2012. Pengaruh Leader Member Exchange (LMX) Terhadap Kinerja Karyawan (Study Kasus Pada Perusahaan Umum Jasa Tirta I Malang), Jurnal Ekonomi Manajemen.

Muljani, Benedicta Djarwati, Taher Alhabsji, dan Djamhur Hamid. 2012. Pengaruh Kepemimpinan Transformasional dan Kualitas Kehidupan Kerja Terhadap Motivasi Kerja dan Kepuasan Kerja Karyawan (Studi Pada Tenaga Pendidik yang Dipimpin oleh Pemimpin Perempuan di Universitas Katolik Widya Mandala Surabaya ), Jurnal Ilmu Administrasi Universitas Brawijaya Malang

Dessler, Garry. 2000. Manajemen Sumber Daya Manusia. Edisi Bahasa Indonesia. Jilid 2. Jakarta : PT. Prenhalindo

Usman, Erik. 2010. Pengaruh Pendidikan dan Pelatihan (Diklat) Terhadap Kinerja Pegawai Pada Kantor Badan Kepegawaian dan Diklat (BKD) Kabupaten Bone Bolango, Jurnal Manajemen Ekonomi

Wijanto, Erin Anggreani dan Eddy M. Sutanto. 2013. Pengaruh Leader Member Exchange Terhadap Kepuasan Kerja, Motivasi Kerja dan Komitmen Organisasional Karywan Departemen Penjualan
Pada PT. X, Agora Vol. 1, No. 1, (2013)

Fahmi, Fikri. 2001. Pengaruh Pendidikan dan Pelatihan Serta Promosi Jabatan Terhadap Motivasi Kerja Di Pertamina APEP Kamojang. Proceeding Of The 5th Inaga Annual Scientific Conference \& Exhibitions, Yogyakarta, March 7 10, 2001

Agustinus, Frans. 2013. Pengaruh Leader Member Exchange Dan Pemberdayaan Melalui Mediasi Komitmen Organisasional Terhadap Kinerja (Studi Pada Kantor Notaris di Propinsi Jawa Tengah), Jurnal Universitas 17 Agustus 1945, Vol 2. No. 2 Tahun 2013

Gomes, Faustino Cardoso. 2000. Manajemen Sumber Daya Manusia. Yogjakarta: Andi Offset

Graen, George B., and Uhl-Bien, Mary. 2002. Relationship Based Approach to Leadership: Development of Leader-member Exchange (LMX) Theory of Leadership Over 25 Years: Applying a Multi-level Multidomain Perspective. Leadership Quarterly Vol. 6, No. 2. Januari 1995: 219-247

Hasibuan, Malayu S.P. 2010. Manajemen Sumber Daya Manusia. Jakarta: Bumi Aksara

Ghozali, Imam. 2006. Aplikasi Analisis Multivariate dengan Program SPSS. Semarang : Undip

Juniantara, I Wayan. 2015. Pengaruh Motivasi dan Kepuasan Kerja Terhadap Kinerja Karyawan Koperasi Di Denpasar, Tesis 
Program Pascasarjana Universitas Udayana Denpasar

Breevaart, Kimberley. 2015. Leadermember exchange, work engagement, and job performance, Article In Journal Of Managerial Psychology, January 2015

Luthans, F., Van Wyk, R. \& Walumbwa, FO. 2007. Recognition and development of hope for South African organisational leaders. Leadership \& Organisational Development Journal, 25(6): 512527

Luthans, F. Youssef dan Avolio. 2007. Organisational behavior.(8th ed.). India: McGraw-Hill

Mathis, R dan Jacks on, J. 2002. Manajemen Sumber Daya Manusia. Jakarta: PT. Salemba Empat Patria

Mangkunegara, AA. Anwar Prabu. 2009. Manajemen Sumber Daya Perusahaan. Cetakan 6. Bandung : PT. Remaja Rosdakarya

Martoyo, Susilo. 2007. Manajemen Sumber Daya Manusia, Edisi 5, Cetakan Pertama. Yogyakarta : BPFE

Marihot, Tua Efendi, H. 2002. Manajemen Sumber Daya Manusia. Jakarta: Grasindo

Nazir, Moh. 2009. Metode Penelitian. Jakarta

Heriyawan, Mohammad Sapta. 2014. Pengaruh Karakteristik Pekerjaan Dan Pemberdayaan Terhadap Kinerja Pegawai Dengan Mediasi Komitmen Organisasional (Studi Pada Politeknik Ilmu Pelayaran Semarang), Kajian Multi Disiplin
Ilmu untuk Mewujudkan Poros Maritim dalam Pembangunan Ekonomi Berbasis Kesejahteraan Rakyat ISBN: 978-979-3649-81-8

Nawawi, H. 2005. Manajemen Sumber Daya Manusia. Yogyakarta: Gadjah Mada University Press

Panggaben, Mutiara S. 2002. Manajemen Sumber Daya Manusia. Jakarta: Ghallia Indonesia

Wulanda, Rika, Nurdin Brasit, dan Nurdjannah Hamid. 2013. Pengaruh Tingkat Pendidikan dan Pelatihan, Motivasi dan Budaya Organisasi Terhadap Kinerja Pegawai Negeri Sipil Sekretariat Daerah Kabupaten Wakatobi, Program Magister Manajemen Fakultas Ekonomi Universitas Hasanuddin

Rivai, Veithzal. 2004. Manajemen Sumber Daya Manusia untuk Perusahaan. Jakarta: PT. Raja Grafindo Persada

Swietenia, Rita. 2009. “Analisis Pengaruh Kepemimpinan, Kompensasi dan Karakteristik Pekerjaan Terhadap Disiplin Kerja Serta Implikasinya Terhadap Kinerja Pegawai (Studi Pada Kantor Pertanahan Kota Semarang)." Jurnal Ekonomi Manajemen - Akuntansi, No. 26, Th. XVI, pp. 96-116

Robbins, S.P. 2006. Perilaku Organisasi: Konsep, Kontroversi dan Aplikasi, Alih Bahasa Hadyana Pujaatmaka, Edisi Bahasa Indonesia, Jilid 1, Jakarta: PT. Prenhallindo

Robbins, S. P. 2007. Organizational Behavior. New Jersey: Prentice Hall

Sastrohadiwiryo, Bejo Siswanto. 2003. Manajemen Tenaga Kerja 
Indonesia Pendekatan Administrative dan Operasional. Jakarta: Bumi Aksara

Astuti, Sih Darmi, Herry Subagyo, Yeri Adriyanto. 2010. Pengaruh Karakteristik Pekerjaan dan Motivasi Terhadap Komitmen Organisasional Serta Dampaknya Terhadap Kinerja Pegawai (Studi pada Balai Penelitian dan Mengembangan Agama Kementrian Agama), Benefit Jurnal Manajemen dan Bisnis Volume 15, Nomor 1, Juni 2010, hlm. 17-28

Sikula Andrew F. 1981. Personnel Administration and Human Resources Management. Willy Trans Edition. New York : John Willey \& Sons, Inc

Simamora, H. 2006. Manajemen Sumber Daya Manusia. Edisi 3. Yogyakarta: STIEYKPN

Sopiah. 2008. Perilaku Organisasional. Yogyakarta: Andi Offset

Suprapti dan Imam Baihaki. 2013. Analisis Pengaruh Pendidikan Pelatihan Dan Motivasi Terhadap Kinerja Pegawai di Lingkungan Dinas Kesehatan Kabupaten Tulungagung, Jurnal OTONOMI, Vol. 13, Nomor 3, Juli 2013

Hadi, Sutrisno. 2006. Metode Penelitian Riset. Yogyakarta : Yayasan Penerbit Fakultas Biologi UGM

Suwatno \& Priansa D. 2011. Manajemen SDM dalam organisasi Publik dan Bisnis. Bandung : Alfabeta

Handoko, T. Hani. 2002. Manajemen Personalia dan Sumber Daya Manusia Edisi 2. Yogyakarta : BPFE
Husein, Umar. 2011. Metode Riset Bisnis. Jakarta : Gramedia Pustaka Utama

Yuli, Sri Budi Cantika. 2005. Manajemen Sumber Daya Manusia, Cetakan Pertama. Malang : UMM Pres

Were M. Susan, W Gakure, E. K Kiraithe dan A.G Waititu. 2012. Influence of Motivation on Performance in the Public Security Sector with a Focus to the Police Force in Nairobi, Kenya, International Journal of Business and Social Science Vol. 3 No. 23; December 2012

Winardi. 2002. Manajemen Kinerja. Edisi ketiga. Jakarta: PT. Raja Grafindo Persada

Yukl, Gary A. 2004. Leadershp in Organizations. Second Edition. Englewood Cliffs. New Jersey: Prentice-Hall, Inc

Yuniarsih, Tjutju dan Suwatno. 2009. Manajemen Sumber Daya Manusia. Bandung : Alfabeta

Zunaidah. 2010. Pengaruh Kompensasi dan Karakteristik Pekerjaan Terhadap Kinerja Pegawai (Studi Empirik Terhadap Pegawai Tetap dan Kontrak pada Perusahaan Menengah dan Besar di Kota Palembang), Jurnal Manajemen dan Bisnis Sriwijaya Vol. 8 No. 15 Juni 2010 